\title{
Mirando a Cuba hoy. Reformas y configuraciones de una nueva etapa. Por Gabriela Pulido Llano, Mario Ayala y Alberto Consuegra Sanfiel, eds. Buenos Aires: Ediciones Imago Mundi, 2016, I49 p.
}

\author{
Martín López Ávalos \\ El Colegio de Michoacán \\ mlopez@colmich.edu.mx

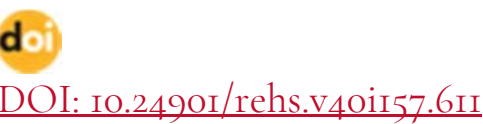

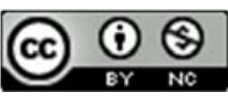

Mirando a Cuba hoy. Reformas y configuraciones de una nueva etapa. Por Gabriela Pulido Llano, Mario Ayala y Alberto Consuegra Sanfiel, eds. Buenos Aires: Ediciones Imago Mundi, 20i6, I49 p. por Martín López Ávalos se distribuye bajo una Licencia Creative Commons Atribución-NoComercial 4.0 Internacional.

El fallecimiento de Fidel Castro el 25 de noviembre de 2016 termina por sellar la transición de su liderazgo político luego de su separación de todos los cargos de responsabilidad en el Estado cubano, primero en 2006 de manera provisional, para ser permanente un par de años después, en 2008, fecha en la cual anuncia su retiro definitivo de la política activa. Desde entonces, el sistema político cubano ha vivido una transición en varios sentidos; los cambios ocurridos en el pasado reciente, a diferencia del pasado, tuvieron a la figura de Fidel más como un referente que como un factor de control. Con Raúl Castro como presidente, Cuba ha dado pasos significativos que se diferencian claramente de las políticas de rectificación que acostumbraba Fidel. La apertura -moderada y limitada- hacia la economía de mercado y el restablecimiento de relaciones diplomáticas con los Estados Unidos se han significado como los dos ejes que marcan las políticas del cambio, o las "reformas y configuraciones" a las que nos convoca el presente libro.

Los editores del libro asumieron los riesgos emanados de la formalización del deshielo que implicaba el restablecimiento de las relaciones diplomáticas y convocaron a un grupo de académicos de varios países ${ }^{\underline{I}}$ para ofrecer una visión de los cambios que se venían produciendo en Cuba. El resultado es esta propuesta para construir una nueva narrativa histórica, sociológica y económica que se diferencia de otros esfuerzos similares al desentenderse del análisis de coyuntura como eje metodológico para ofrecernos una historia del presente, de tal manera que la propia estructura del texto nos lleve a mirar los diversos contextos que hacen posible las explicaciones políticas y económicas sin perder de vista la interpretación historiográfica. Tanto 
los editores como los autores participantes asumen la importancia de la geopolítica como marco para justificar el abordaje colectivo y colaborativo en el que se embarcaron; para tal fin suponen que Cuba tiene un destino importante que jugar en el futuro cercano. El punto de quiebre, sin embargo, es la categoría clave aparecida con el fin de la guerra fría: la transición. Sin ésta no sería posible establecer las dinámicas deseables, posibles, y realizables que la elite política cubana emprendió desde la década de i990.

Más allá de la historiografía temática y el análisis coyuntural propio de las ciencias sociales, el valor del presente libro está en ser un ejercicio de historia (multidisciplinaria) del presente. Se trata de abrir una puerta que a su vez nos lleva a abrir otra puerta, es decir, cada una de las partes es el resultado de un conocimiento experimentado que lleva a plantearnos cuestiones de fondo para explicar el presente, de tal forma que la secuencia de las colaboraciones tienen una lógica que va de la reflexión de la historiográfica política para entender cómo y por qué se construyó el presente tal y como lo conocemos desde el acontecimiento definido como Revolución cubana, para luego pasar a la estructura del modelo de la economía que la elite política le plantea a la sociedad: libre mercado sí, pero regulado, aprovechando los flujos de inversión del capitalismo global, además de apelar al esfuerzo individual y familiar a través de la migración. Los temas concluyen con una mirada a la juventud cubana actual, buena parte de ella llegada a la adolescencia justo con el retiro político de Fidel Castro y a la edad adulta en el momento de su muerte, de tal forma que la nueva generación es producto de la crisis terminal del socialismo soviético y del periodo especial cubano, donde la épica de la Revolución como el gran acontecimiento que definió a Cuba no es más que un referente histórico, no una vivencia como lo fue para las dos generaciones anteriores. El hecho es relevante en la medida que conforma nuevas experiencias y, sobre todo, expectativas, que ya no tienen nada que ver con las que tuvieron sus padres y abuelos. En buena medida este cambio podría significar el fin de la excepcionalidad cubana que marcó su construcción historiográfica en el medio siglo inmediato anterior. A partir de ahora, Cuba deja de tener esa aura que significó la Revolución para ser un país más, con los mismos problemas que cualquier otro y que, adicionalmente, tendrá que competir por los recursos y capitales globales siempre en disputa ofreciendo mejores condiciones para su reproducción. ${ }^{2}$

\section{Modelo en construcción}

En el libro encontramos reflejadas las nuevas tensiones, composiciones y dilemas de la clase política cubana y, por ende, de su elite. Lo que nos muestra la parte dedicada a la estructura es que el nuevo modelo está en disputa y se encuentra en proceso de construcción. En esa medida, sin embargo, podemos distinguir dos escenarios: uno difuso y complicado para medir, basado en el fortalecimiento de la sociedad civil (todavía no organizada) que se está gestando con los diversos matices del "emprendedor", pero que en realidad está en la formación de un renacido espíritu en el capitalismo cuya cabeza visible son los "cuentapropistas", ahora no sólo tolerados sino fomentados por el gobierno.

El libro debe verse para leer lo que puede pasar después de 20I8, cuando seamos testigos del relevo generacional de la elite castrista, cuando Raúl Castro se retire de la presidencia y desde 
la jefatura del Partido Comunista de Cuba mantenga el control (si la naturaleza se lo permite) sobre su sucesor designado.

En la composición del libro también se puede apreciar la geopolítica de la producción académica, es decir, lo que se produce dentro y fuera de Cuba. Resaltan las limitaciones de la academia cubana por asumir un papel de crítica al proceso político de la transición. Su manufactura se encuentra atada a las directrices marcadas por el Partido, esto es, repiten el diagnóstico emitido desde arriba, apegándose a las expectativas marcadas por el discurso político que deja a salvo de cualquier crítica a los verdaderos tomadores de decisiones (Fidel y Raúl), circunscribiendo el problema a las deficiencias de la "gestión administrativa" y a las secuelas de las diversas crisis que vienen del exterior e impactan a Cuba. Si bien son entendibles las circunstancias por las que tienen que pasar los académicos cubanos-dada la naturaleza del sistema político- para ver publicados sus trabajos, la subordinación al discurso político hegemónico en turno va minando sus posibilidades de ofrecer a la sociedad cubana caminos diferentes a los ya definidos por el poder político.

Por último, no está de más señalar el paralelismo de las coyunturas: una la de 20r4, que abrió nuevas expectativas positivas en torno al cambio; y la actual, abierta en la elección presidencial de noviembre de 2016 en Estados Unidos. La elección del candidato republicano Donald Trump con su retórica populista ultraderechista mantiene en vilo lo logrado en este año y medio pasado. No estaría de más dar seguimiento a este asunto entre la toma de posesión de éste como presidente en enero de 2017 y la anunciada salida de Raúl Castro de la presidencia de su país en 20I8. ¿Volveremos al pasado que creíamos superado?

\section{Notas}

I Por orden de aparición en el libro: Rafael Rojas (CIDE, México); Martín López (Colmich, México); Luis Suárez Salazar (Instituto Superior de Relaciones Internacionales "Raúl Roa", Cuba); Carmelo Mesa-Lago (Universidad de Pittsburg, Estados Unidos); Daniele Benzi y Mónica Vergara (Universidad Andina Simón Bolívar, Ecuador); Ileana Sorolla Fernández (Centro de Estudios de la Migraciones Internacionales, Universidad de La Habana, Cuba); María Isabel Domínguez García (Grupo de Estudios sobre la Juventud, Centro de Investigaciones Psicológicas y Sociológicas, Cuba).

2 Carmelo Mesa-Lago calcula que Cuba requiere de un mínimo de i,8oo millones de euros al año como inversión extranjera directa mínima para poder mantener un ritmo de crecimiento aceptable en los primeros años de la transición al libre mercado. Sin embargo, la pregunta que queda sin responder es que esta cantidad vendrá de la disputa con otros países de la región Circuncaribe primero, y del resto del mundo después. Los años dorados del apoyo soviético y de la solidaridad bolivariana de Venezuela a favor de Cuba terminaron, lo que pondrá en evidencia la capacidad de la elite política para moverse en un mundo desconocido, fuera de la excepcionalidad revolucionaria que le permitía mantenerse al margen de esta competencia por el financiamiento internacional. 